\title{
You Perceive What You Believe: The Impact of Psychological Beliefs on Perceived Technostress
}

\author{
Julia Theresia Zielonka \\ Johannes Gutenberg-Universität Mainz \\ julia.zielonka@uni-mainz.de
}

\author{
Franz Rothlauf \\ Johannes Gutenberg-Universität Mainz \\ rothlauf@uni-mainz.de
}

\begin{abstract}
Research in technostress examines how and why the use of information and communication technologies causes individuals to experience an imbalance between demands and the ability to meet them. In this paper, we develop a new approach for explaining differences in the perceived level of technostress between individuals. We propose that psychological beliefs have an impact on the level of perceived technostress. In a web-based survey $(N=159)$ we collected data on perceived technostress and two essential beliefs, namely locus of control and self-efficacy, to test our proposition. The results confirm that perceived technostress is significantly dependent on the individual's beliefs. In particular, the higher the sense of self-efficacy of an individual is, the lower is the level of perceived technostress. Similarly, individuals with an internal locus of control are less prone to technostress than individuals with an external locus of control.
\end{abstract}

\section{Introduction}

Information and communication technologies (ICT) have been increasingly permeating our lives for decades. Whereas the common introduction of computers at work in the 1980s was only affecting professionals working in certain positions, the invention of the smartphone was already intended to serve people in their private life as well. At the latest with the advent of the Web2.0 and social media, information and communication technologies have become ubiquitous in our society. At the same time, ICT users are not only passive consumers but also have become active content authors and creators. Thanks to ICT we have rapid and easy access to information and we can easily stay connected with whoever we want around the globe. In fact, ICT disregard any time or space boundaries and were intended to make our professional and private lives easier, more efficient and more enjoyable. However, as soon as the first computers were introduced to workers in their professional environment in order to support and increase their performance, negative aspects obviously emerged, too. Users showed resistance to new technologies in terms of unwillingness and inability to learn to effectively use the supposed supportive technological resources [15]. Brod [16] was the first researcher who coined the term technostress as "the inability to adapt or cope with new computer technologies in a healthy manner".

Technostress has become a growing area of scholarly investigation in psychology as well as in information systems research because of its interdisciplinary nature and the theoretical links in literature [61, 70]. Nowadays, the definition of technostress in the area of information systems research has broadened to the feeling of stress which users experience due to the usage of ICT [70, 72]. Stress is an adaptive response to so called stressors which are factors evoking feelings of distress inside an organism [30, 43, 46, 67]. With regard to technostress, ICT represent the stressors affecting individuals' wellbeing leading to negative outcomes such as feelings of hassle, helplessness, anxiety, resistance, technophobia and mental fatigue [51, 67]. In addition, studies revealed that technostress does not only have an influence on the individual's psychological health but also on its physical one with symptoms like headache, muscle cramps, insomnia, and joint aches [21, 33, 69].

As the effects of technostress on individuals are manifold, scholars are investigating the nature of technostress with its causes and consequences in order to explain this phenomenon and to find possible solutions for prevention of the occurrence of technostress [26, 32]. There are plenty of studies examining the sources of technostress $[33,70]$. These suggest to level the exposure to ICT to find a healthy balance while using modern technologies [24]. Another approach deals with individuals' coping strategies to decrease technostress [55, 65]. However, coping is 
only necessary when technostress already occurs and exerts its negative effects on the person.

We argue that effective strategies tackling the problem and the effects of technostress need to focus on the part before technostress ever evolves in the individual. Recent studies have taken this approach into account by examining possible moderators influencing the stressor-outcome relationship such as technology competence or technology self-efficacy [33, 65, 67, 71]. There are also studies looking at the relationship between certain personality traits and technostress [37, 40, 47, 67]. We, however, introduce a novel approach by arguing that perceived technostress depends on the individual's psychological beliefs. In contrast to current literature explaining the level of perceived technostress based on individuals' personality characteristics or innate technology competence, psychological beliefs are not stable over time $[42,60]$. They can be rather trained and changed towards a desired outcome [41, 54, 78]. This malleability of beliefs raises the interest in looking closer at the impact of beliefs on perceived technostress. If the level of perceived technostress depends on the individual's beliefs, then technostress can be regulated by changing or form desired beliefs.

In this paper, we theoretically develop and empirically study the correlation between psychological beliefs and perceived technostress. The goal of this study is to show that perceived technostress depends on the individual's psychological beliefs. In order to test our hypotheses we select two representative beliefs, namely self-efficacy and locus of control, which are widely recognized beliefs in psychology literature and adjunct areas of research. Based on the definition of technostress, beliefs, and the two constructs in focus, we derive the theory lying behind a possible correlation between technostress and beliefs. As a first proof of our theory, we conducted a survey with 159 individuals. We perform a statistical analysis and present and discuss the results in section 5 and 6 respectively. Finally, concluding comments and future research directions are given.

\section{Technostress}

A realistic and widely used concept of the phenomenon of stress is the processual approach which is based on the Transactional Theory of Stress [30, 43, 46]. According to this view, stress is not inherent in the environment nor in the individual. It is rather an ongoing process of adaption based on a transaction between an individual and its environment. The external forces that impinge on the organism of the individual are named stressors [30, 43, 52]. The elements of this theory are the ongoing perception, cognitive appraisal of potential stressful situations in life, affect and the individual's coping efforts [45]. A situation is perceived or appraised as stressful when demands exceed a person's resources or capabilities and the person appraises this situation as harmful. Then, coping processes begin to manage the troubled individual [43, 46]. These processes affect the individual's subsequent appraisal which encompasses the evaluation of the individual's abilities of coping with the stressors [44, 45]. This whole transaction unfolds the intensity and level of the stress reaction and perception. Therefore, appraisal as the evaluation of the significance of the situation on the individual's well-being, and coping as the psychological and physiological efforts to manage these demands, are key concepts in Lazarus' theory of stress [30, 43].

Brod [16] is known to be the first who labeled stress in association with the usage of ICT as technostress. Lazarus' transactional stress model within the field of cognitive psychology is the widely adopted conceptual basis for the comprehension of technostress $[24,33,56,71]$. The concept of

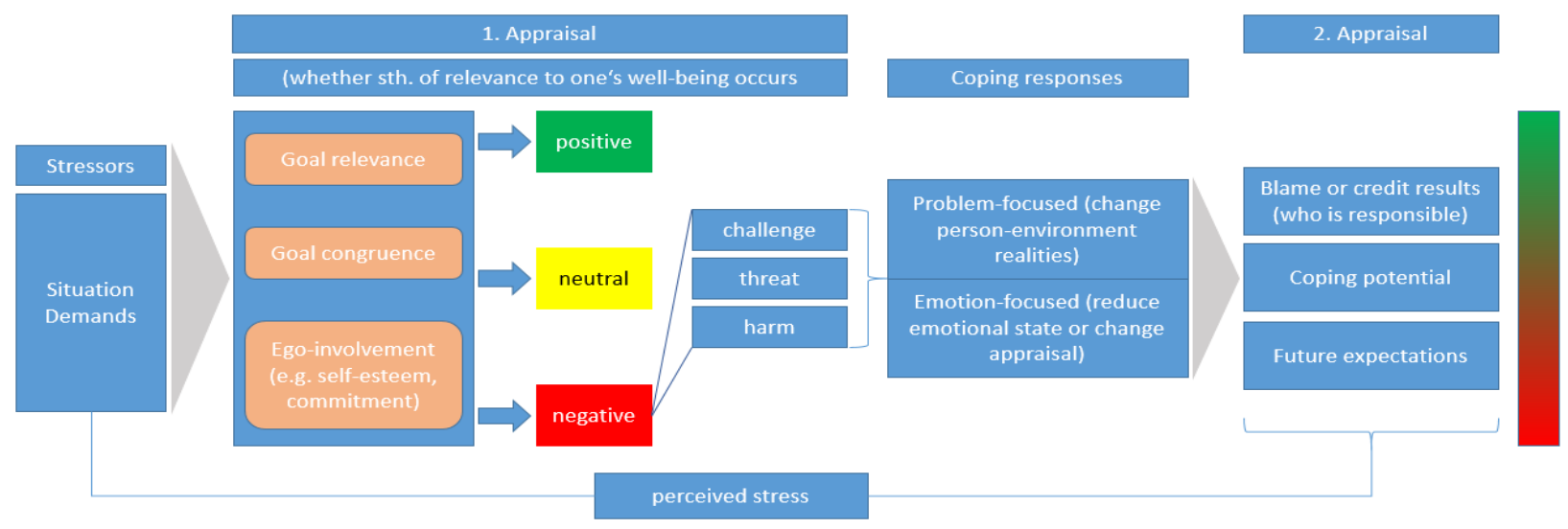

Figure 1. Transactional technostress model 
technostress addresses contexts in which stress processes are initiated by the use of ICT $[56,70]$.

Figure 1 demonstrates the components of the transactional technostress model. First, so-called stressors in form of a situation or demands encompassing technology usage, which exceed the individual's resources or abilities, must be present. Second, the individual reconciles the environmental demands with its goals by evaluating if the demands are congruent with its goals and if they are relevant to her. In addition, the appraisal is also dependent on the individual's ego-involvement, such as self-esteem. Based on the preceding classification the individual appraises the environmental technostressors as irrelevant, positive or negative. The negative appraisal can be distinguished in threat, harm, or challenge. Third, there are two coping responses. With problemfocused coping the individual tries to change the person-reality environment, e.g. by reducing her exposure to technology (technostressors) or by training of necessary technology skills to meet the demands. With emotion-focused coping the individual tries to reduce its emotional state towards the demanding situation or change its primary appraisal of the technostressors. In contrast to problem-focused coping, emotion-focused coping addresses the cognitive psychological efforts to manage the perceived stressful situations. Fourth, the second appraisal concerns the evaluation of the individual's coping responses and their possible success. The components of the secondary appraisal include blame or credit results (e.g. who is responsible for the demanding situation), coping potential (e.g. evaluating if the behavioral or cognitive operations will positively influence the outcome), and future expectations (e.g. evaluating the further course of the situation focusing on its goal congruence or incongruence). Hence, the secondary appraisal influences the interplay of the technostressors and the coping responses. This model posits that technostress is not a single component of a process (e.g. response, stimulus) but rather it is the process itself which may lead to negative effects for individuals [30, 44, 70].

This transactional model of technostress constitutes the conceptual foundation of many studies $[33,67,71]$. Most of the research focuses on either the stressors [11, $51,73]$ or the negative effects of the stressors [33, 56, 66]. Previous research identified five major technostressors: techno-overload [24], technocomplexity [12], techno-invasion [72], technoinsecurity [72], and techno-uncertainty [51]. There is evidence that outcomes of the technostress process include exhaustion, burnout, strain [17, 19, 33] and also physiological symptoms such as headache, muscle cramps, insomnia and joint aches [21]. A lot of research focused on job related outcomes of technostress and revealed that technostress leads to lower job satisfaction and commitment, turnover intentions, anxiety, depression, lower productivity, and lower innovation [56, 69, 72, 79].

There are also studies looking at the coping responses of individuals experiencing technostress, such as disengagement with ICT or adaption to the requirements of ICT usage [13, 14, 24, 77]. Coping, however, is a response to the appraised situation. Meaning that coping is an anticipating reaction due to the upcoming perception of stress based on the first appraisal of the situation [46]. Thus, coping is necessary when stress already has arisen in order to lower the perceived stress level afterwards.

Even though a lot of studies might explain when the level of technostress is perceived as higher or lower, or as to how individuals are able to cope with technostress, why do some people experience a certain exposure to ICT as more stressful than others? This question is tackled in a few studies by the inclusion of moderators of the technostressor-outcome relationship. Tarafdar et al. [71] were able to show that technology competence is a moderator of the technostressoroutcome relationship that decreases perceived technostress. Srivastava et al. [67] looked at personality orientations such as agreeableness, extraversion, and neuroticism. According to the descriptive summaries approach, personality traits are the descriptive summary of individuals' habitual patterns of thoughts, emotions and behavior. Opposed to beliefs, personality traits are viewed as dispositions and, thus, stable over time [37, 41, 60].

Lazarus' [44] transactional stress model, however, stipulates that stress is a process involving two appraisals which form the central sources of stress. These two appraisals represent the inner evaluation of a certain situation or demands and the possible coping responses [46]. Thus, the foundation of these appraisals lie in the individual's mind, namely in its psychological beliefs. Lazarus [44] already pointed out that beliefs are central to appraisal and coping response [45], however, he did not dig deeper into this cognitive process [22]. Possibly, this is the reason why technostress has not been related to psychological beliefs yet. Examining the relationship between beliefs and technostress is relevant since beliefs manifest an approach that addresses the first and the second appraisal as well as coping responses. Existing literature already examined personality traits as dispositional factor for the level of perceived technostress [37, 40]. In contrast to the personality traits approach, beliefs are not static but rather can be trained and formed over time [41, 54, 60, 78]. 
In addition to existing technostress research, relating technostress to beliefs opens up the possibility to explain who perceives stress and why is there a difference in the perception of stress between individuals. According to the transactional stress model, technostress is the product of an individual's interaction with environmental demands (technostressors) [30, 43]. We argue that if individuals do not appraise the demands as technostressors (or at least less), they will not perceive any technostress (or at least less). Therefore, our study focuses on the beliefs of individuals, which are the psychological basis of any appraisal or coping response. At the same time, we can also infer which individuals will be more successful in coping with technostress since certain beliefs help to cope with technostress better.

\section{Psychological beliefs}

There are human behaviors that people are aware of and, thus, are able to control them [1, 7, 9, 25]. Studies on implicit social cognition, however, show that factors which lie outside of people's awareness have an impact on their behaviors, decisions and judgments, too $[1,35$, 63]. Scholarly research found evidence that both intentional and unintentional behaviors and actions are influenced by people's psychological beliefs [1, 35].

In general, beliefs are convictions that certain propositions in an individual's mind are true [4, 27]. More specifically, beliefs refer to a person's "subjective probability of a relation between the object of belief and some other object, value, concept, or attribute" [29]. This implies that the creation of a link between any two components of an individual's world is immanent in the formation of a belief. Hence, there are different processes underlying the formation of a belief. First, descriptive beliefs are established by the direct observation. Second, inferential beliefs are actively formed by the inference from other already existing beliefs. Third, informational beliefs are based on other sources which the individual accepts as truth [29]. Based on the formation processes of beliefs, it is inferable that beliefs are non-static but rather flexible and can be formed or trained over time. It is an associative process where the stimulus-attribute cooccurrence are repeated with frequency where the perceiver learns the belief as a result of this exposure [41, 54, 60, 78].

In contrast to attitudes, beliefs are non-evaluative, meaning that a belief is neither positively nor negatively evaluated by the individual. Attitudes decide whether someone likes or dislikes an object or a relationship. According to Ajzen's theory of planned behavior [1], "beliefs are the building blocks for the formation of attitudes toward a behavior, subjective norms, the perceptions of behavioral control, and ultimately behavioral intentions" [2].

Relating the concept of beliefs with the process of stress both include one basic component: the relationship between two objects. Beliefs are a link between two components which is held to be true by the individual [29]. Similarly, stress is the transaction between two components, namely the person and its environment [43]. Therefore, we argue that an individual's basic psychological beliefs are closely connected to the same individual's stress perception. Precisely, technology in the presence of ICT (demands/situation) represents one of the two components while the other component is embodied in the rest of the stress transactional process. During the psychological appraisal processes, individuals assess based on their beliefs, which form the link between ICT and technostress experience, if and to what extent ICT represent a threat to them and how to cope with them (Figure 1). Fishbein and Ajzen [29] point out that beliefs form the fundamental determinant of the dependent variable, which is technostress in our study presented. In order to prove the existence of the impact of beliefs on perceived technostress, this paper focuses on two basic beliefs, which have already caught a lot of attention in psychology research and adjacent areas: locus of control and self-efficacy.

\subsection{Locus of control}

Rotter [59] coined the term locus of control and defines it as an individual's belief as to how this individual is able to affect the outcome through his own actions. In general, it is the belief about an individual's perception about the cause of events in his life. Scholars distinguish between internal locus of control and external locus of control [3, 48, 59].

Internal locus of control refers to the belief that the cause of a situation or action depends on the individual's internal force. An individual's own decisions, actions, and efforts decide or impact the course of his life and what will happen [48]. Individuals with an internal locus of control tend to apply problem-focused coping behaviors [53]. They are also more likely to reduce or eliminate stressors, which they perceive as stressful [76]. We go a step further and argue that individuals with high locus of control perceive less technostress because they are more likely to appraise stressors as not stressful.

Hla: Individuals with an internal locus of control perceive a lower level of technostress.

In contrast to individuals with internal locus of control, people with an external locus of control believe that situations and actions are not within their 
control but some external force determines their course of life. Accordingly, they are more likely to believe that their life is controlled and influenced by other people, or luck and fate and that they are helpless and are not able to change the current situation to the better $[48,59]$. Therefore, people with an external locus of control are more likely to feel unable to eliminate stressors [76]. Taking into account the diminished sense of self-control, we expect that individuals with an external locus of control are more likely to experience technostress than their counterparts with an internal locus of control.

Hlb: Individuals with an external locus of control perceive a higher level of technostress.

\subsection{Self-efficacy}

According to Bandura [10], self-efficacy is "the belief in one's capabilities to organize and execute the courses of action required to produce given levels of attainments" [10]. In general, self-efficacy refers to the individual's belief in her own perceived ability to succeed, specifically the ability to encounter challenges and demands successfully $[9,10,50]$.

In contrast to locus of control, self-efficacy is the belief in an individual's own ability to succeed whereas locus of control refers to where the individual believes the power to change a situation resides, that is either within the individual (internal locus of control) or outside the individual (external locus of control) [10, 59, 76]. Logically, there are findings that an internal locus of control is positively correlated with a high sense of self-efficacy [5]. Self-efficacy beliefs shape the course of a person's life by determining the types of activities, demands and situational environments she chooses. Individuals only pursue activities they believe they can master and they avoid situations which they believe would exceed their capabilities to handle them. Self-efficacy also impacts the level of effort individuals spend to reach their goals and how they cope with difficulties and failures. Thus, the belief in one's self-efficacy has an impact on all from psychological states over motivation to behavior [8].

Low self-efficacy gives rise to the feelings of anxiety and stress because it fosters the perception of being unable to influence and cope with stressors. The believed inability to turn off disturbing thoughts is the major source of perceived stress. Hence, self-efficacy is "a key factor in regulating thought produced stress" [8] as it affects the appraisal and coping processes in Lazarus' transactional stress model.

Already Bandura [8] proposed that the belief in self-efficacy influences how individuals encounter stressors and which coping strategies are chosen. This cognitive process goes along with the individual's determination of the level of effort necessary to reach her goal facing these stressors. People with high selfefficacy do believe that they have the power and abilities to successfully control or change stressful situations $[8,10]$. More precisely, a high sense of selfefficacy lowers the chance that feelings of technostress are perceived. Therefore, we argue that self-efficacy is negatively correlated with perceived technostress.

H2: The higher the belief of self-efficacy is, the less technostress is perceived.

\section{Methodology}

As technostress and beliefs are individual perceptions, we collected the necessary data for our analysis with a web-based survey. We invited prospective participants via email and social media to participate in our survey and to forward the invitation to their friends and colleagues. The target population for this study was not limited to any specific profession as we intend to analyze and understand the impact of beliefs on technostress in general. Even though there are critical opinions about online panels arguing that self-reported values are not objective, there are also unneglectable advantages of this way of data collection, for example, reaching individuals of a variety of different backgrounds and enabling full anonymity [24, 49]. Furthermore, stress is an individual perception, so self-reports are one of the key techniques to capture stress measures. The same is true for beliefs. The participants were asked about their general experience regarding stress perception when using ICT. The collected data includes constructs for the beliefs of locus of control and self-efficacy as well as for technostress. In addition, we controlled for demographic data including gender, age, and highest educational qualification.

The items for each construct are withdrawn from scholarly validated scales which we used in an original, reworded or adapted version. Specifically, locus of control was measured by the scales of Craig et al. [23] and Wang et al. [75]. Self-efficacy was assessed by the validated questionnaires of Sherer et al. [64] and Chen et al. [18]. The questions to measure technostress were taken from Ayyagari et al. [6]. Respondents answered the items in form of assertions about technostress, locus of control and self-efficacy using a five-point Likert scale ranging from 1 (I do not agree at all) to 5 (I totally agree). To be more precise, the higher the agreement to the statements, and with it its allocated points, the more the respondent exhibits an internal locus of control, and the higher is her self-efficacy belief. 


\section{Results}

In total, 159 individuals $(54.5 \%$ female) responded to our web-based survey. We controlled for the time used to answer the questionnaire to avoid the inclusion of mere click-throughs. The respondents' age ranges from 19 to 65 years. The highest educational degree earned by $55 \%$ of the respondents is a university degree. In order to test our hypotheses, we performed an analysis of the collected data. We applied partial least squares structural equation modeling (PLS SEM) as it is a strong data analysis technique, which is also extensively used in information systems research [39]. In addition, PLS SEM does not assume any specific data distribution and is also applicable for smaller sample sizes [20]. First, we conducted a confirmatory factor analysis to validate and sharpen the constructs of technostress, locus of control and self-efficacy. Based on these results we included the items with the highest loadings with a value of 0.7 and above for the representation of the constructs.

\subsection{Measurement model}

We test the reliability and validity of the constructed measures [58]. Table 1 demonstrates that the average variance extracted (AVE) for all constructs exceeds the necessary threshold of 0.5 confirming the validity of our constructs [31]. To ensure the reliability of the measures, we calculated the composite reliability. All values exceed the required threshold of 0.6 and, therefore, confirm the reliability of our constructs measurement.

Table 1. Validity and reliability statistics of the measurement model

\begin{tabular}{|l|c|c|}
\cline { 2 - 3 } \multicolumn{1}{c|}{} & $\begin{array}{c}\text { Average Variance } \\
\text { Extracted }\end{array}$ & $\begin{array}{c}\text { Composite } \\
\text { Reliability }\end{array}$ \\
\hline Technostress & 0.568 & 0.839 \\
\hline Locus of Control & 0.610 & 0.757 \\
\hline Self-Efficacy & 0.553 & 0.861 \\
\hline
\end{tabular}

Table 2. Fornell-Larcker criterion test results

\begin{tabular}{|l|c|c|c|}
\cline { 2 - 4 } \multicolumn{1}{c|}{} & $\begin{array}{c}\text { Locus of } \\
\text { Control }\end{array}$ & $\begin{array}{c}\text { Self- } \\
\text { Efficacy }\end{array}$ & Technostress \\
\hline Locus of Control & 0.781 & & \\
\hline Self-Efficacy & 0.188 & 0.744 & \\
\hline Technostress & -0.361 & -0.301 & 0.754 \\
\hline
\end{tabular}

Table 3. HTMT criterion test results

\begin{tabular}{|l|c|c|}
\cline { 2 - 3 } \multicolumn{1}{c|}{} & Locus of Control & Self-Efficacy \\
\hline Self-Efficacy & 0.381 & \\
\hline Technostress & 0.656 & 0.361 \\
\hline
\end{tabular}

Table 2 reports the Fornell-Larcker criterion test results, which measure the discriminant validity. All measures meet the required criteria [31]. In addition, we also controlled for discriminant validity with the HTMT criterion (Table 3). The values are below 0.85 indicating discriminant validity $[34,36]$.

\subsection{Structural model}

We test the structural model for multi-collinearity based on the variance inflation factor (VIF). The VIF values are 1.037, which is below the threshold of 3 . This indicates no multi-collinearity between the constructs $[38,62]$.

As it can be seen in table 4, the statistical analysis confirms all of our hypotheses. Both coefficients of the belief variables are negative (Model A). In particular, the higher the individual's (internal) locus of control, the less technostress she perceives. The statistics indicate this relation with a significance at the 99\% level. In addition, the higher an individual's belief of self-efficacy is, the less technostress is perceived. This inference is also supported by the results at a significance level of $99 \%$.

\section{Table 4. Coefficients}

\begin{tabular}{c|cc}
\multicolumn{2}{c}{ A } & $B$ \\
\hline Locus of Control & $-0.316^{* *}$ & $-0.327 * *$ \\
Self-Efficacy & $-0.241^{* *}$ & $-0.209^{*}$ \\
Age & & 0.069 \\
Highest Degree & \multicolumn{2}{c}{0.105} \\
No. ICT devices & 0.187 & 0.024 \\
$R^{2}$ & 0.176 & 0.205 \\
Adj. $R^{2}$ & 0.174 \\
* indicates significance at the 95\% level \\
** indicates significance at the 99\% level
\end{tabular}

We also controlled for age, highest degree earned, and number of ICT devices owned by the individual (Model B). By adding these control variables to the regression model, the coefficients of locus of control and self-efficacy remain negative at significance levels of $99 \%$ and $95 \%$ respectively.

The variable age exhibits a positive coefficient, meaning that with increasing age the level of perceived technostress increases, too. However, this result is not significant. The number of ICT devices owned by the individual does not play a significant role in the model either. The variable indicating the highest degree earned by the respondent shows that there is a negative correlation with perceived technostress. However, this result is not significant either.

Even though, the regression model supports our hypotheses, adjusted $\mathrm{R}^{2}$ indicates, that only $17.6 \%$ of variance can be explained with this model. Even when 
adding control variables to the model, $\mathrm{R}^{2}$ does not grow to more than $20.5 \%$. However, as $\mathrm{R}^{2}$ is inflated by the inclusion of non-significant control variables, it is necessary to look at adjusted $\mathrm{R}^{2}$, which even slightly decreases to $17.4 \%$. This indicates that the control variables do not impact our model. However, there must be further factors contributing to perceived technostress. As in the theory section explained, we focused on only two beliefs which theoretically contribute to the appraisal and therefore to perceived technostress. Hypothetically, adding more belief constructs to the model would increase adjusted $\mathrm{R}^{2}$.

\section{Discussion}

The outcomes confirm all of our hypotheses. The results, hence, support the view that psychological beliefs affect the perception of technostress. In particular, beliefs influence the level of perceived technostress. Individuals with an internal locus of control and with a high self-efficacy belief tend to perceive less technostress than individuals with an external locus of control and with a low level of selfefficacy belief.

An individual with an internal locus of control believes that her own decisions, actions and efforts determine the course of her life [48]. Hence, individuals believing that the power to control life lies within themselves feel less threatened by external stressors, which may occur in the form of ICT or ICT related demands, because they believe that it is themselves who control the situations and their outcomes. Therefore, individuals with internal locus of control tend to appraise technostressors (first appraisal) and coping strategies (second appraisal) differently compared to people with external locus of control. As individuals with internal locus of control believe that the power to control lies within the individual, they appraise potential stressors as less harmful, which leads to a lower level of perceived technostress.

Similarly, individuals exhibiting a high level of self-efficacy believe in their own ability to succeed and to encounter challenges and demands successfully [9, 10, 50]. Consequently, individuals with the belief to be able to master potential stressors successfully perceive a lower level of technostress as they appraise stressors as less harmful to them.

According to the transactional technostress model, technostress is a process of interaction between the individual and the environment (including first and second appraisal) and only the whole transaction unfolds the level of perceived technostress. Therefore, the beliefs do not only affect the appraisal of demanding situations in terms of stressors but they also influence the appraisal of one's coping strategies and abilities.

Our results demonstrate that the beliefs in internal locus of control and in high self-efficacy decrease the level of perceived technostress. Hence, we follow that beliefs are an important factor of Lazarus' transactional appraisals $[43,46]$ that affect the perception of technostress.

Adding the control variables age, highest degree earned, and number of ICT devices owned does not increase the variance explained in the model nor do these variables show any significant effects on perceived technostress. This outcome corresponds with previous studies in the area of technostress [74].

\section{Implications, limitations, and outlook}

The goal of this study presented was to examine if psychological beliefs have an impact on perceived technostress. In order to test our hypotheses, we conducted a web-based survey with 159 participants where we collected data on perceived technostress and two relevant beliefs, namely locus of control and selfefficacy. The results clearly support our postulations that beliefs have a significant effect on perceived technostress. In particular, the higher the belief of internal locus of control in the individual is, the lower is the level of perceived technostress. Likewise, individuals with a higher sense of self-efficacy perceive less technostress. These findings contribute theoretical as well as practical implications. Our findings support the approach of considering the appraisals in the transactional stress model as a major factor affecting the process of technostress perception. When appraising potential stressors or coping strategies, the individual reconciles the environmental demands with her goals. During this transactional process, beliefs build an essential determinant for the extent of perceived technostress. Thus, our study advances the understanding in technostress regarding the role of beliefs as means to steer the perception of technostressors as we theoretically extend on the classic transactional stress model by introducing beliefs as significant determinants of the level of perceived technostress.

Regarding the fact that beliefs can be trained and, therefore, changed, our evidence that beliefs significantly influence technostress perception implicates that the level of perceived technostress can be controlled by helping people develop the beliefs they need to lower their stress perception.

Despite the fruitful findings, this study also comes along with some limitations. First, we focused only on two psychological beliefs in this study. We acknowledge that there is a variety of other beliefs that 
still need to be examined in a technostress context. It is of interest to find out what other kinds of beliefs lower the level of perceived technostress. With this information researchers as well as practitioners know what kind of people are more likely to perceive technostress and what kind of beliefs need to be trained in order to develop people who are less susceptible to technostress. In addition, this study focused on technostress stemming from the psychological perspective. According to sociological [68] and neurophysiological perspectives [57] to technostress, however, there might be elements of technostress that cannot be controlled solely by adjusting ones beliefs.

Second, even though self-reported measures of the construct variables have several advantages, technostress research should try to overcome possible limitations of one single approach by combining different measurement methods. We suggest following a multi-method approach for upcoming studies in this area of research, for example, by combining selfreported and physiological measurements of technostress to measure constructs more subconsciously [28, 69]. In addition, studies in real life scenarios or experiments need to be conducted in order to capture the human measurements when the individuals are exposed to real technostressors. It is of further interest to discover if there are significant differences in the outcomes of our study compared to real life experimental studies.

Third, the relatively small sample size of 159 participants might not entirely represent the general population. This may result in biased data (e.g. nonresponse bias). In addition, the survey measured the general beliefs and perception of technostress. Accordingly, it is of interest to investigate in future studies whether our findings also apply in other specific contexts.

We view this study as a discussion opener and first approach to introduce the concept of psychological beliefs for a new perspective to understand and examine the phenomenon of technostress. We also consider the evidenced impact of beliefs on the perception of technostress in this study as a good basis for upcoming research. Our intention is to extend our research with more types of beliefs and with a multimethod measurements approach, which can elucidate more the under-explored field of beliefs in technostress research. In addition, it is of interest to integrate our findings in existing technostress models and examine their impact on these. In this study, technostress is defined as distress, meaning that technostress evokes negative feelings and outcomes for the individual. Stress, however, can also induce positive feelings and outcomes. This kind of technostress is termed technoeustress $[70,80]$. As techno-eustress is a relatively new research direction, we also suggest looking at the impact of beliefs on techno-eustress.

\section{References}

[1] Ajzen, I., "The theory of planned behavior", Organizational Behavior and Human Decision Processes 50(2), 1991, pp. 179-211.

[2] Ajzen, I., and N. Dasgupta, "Explicit and Implicit Beliefs, Attitudes, and Intentions", In The Sense of Agency. Oxford University Press, 2015, 115-144.

[3] Anderson, C.R., "Locus of control, coping behaviors, and performance in a stress setting: A longitudinal study.", Journal of Applied Psychology 62(4), 1977, pp. 446-451. [4] Anderson, C.R., M.R. Lepper, and L. Ross, "Perseverance of social theories: The role of explanation in the persistence of discredited information", Journal of Personality and Social Psychology 39, 1980, pp. 1037-1049. [5] Au, E.W.M., "Locus of control, self-efficacy, and the mediating effect of outcome control: predicting course-level and global outcomes in an academic context", Anxiety, Stress, \& Coping 28(4), 2015, pp. 425-444.

[6] Ayyagari, R., V. Grover, and R. Purvis, "Technostress : technological antecedents and implications", Management information systems : mis quarterly 35(4), 2011.

[7] Bandura, A., Social foundations of thought and action: a social cognitive theory, Prentice-Hall, Englewood Cliffs, NJ, 1986.

[8] Bandura, A., "Self-Efficacy”, In V.S. Ramachaudran, ed., Encyclopedia of human behavoir. Academic Press, New York, NY, USA, 1994, 71-81.

[9] Bandura, A., Self-efficacy: the exercise of control, Freeman, New York, NY, USA, 1997.

[10] Bandura, A., "Personal and collective efficacy in human adaption and change", In J.G. Adair, D. Bélanger and K.L. Dion, eds., Advances in psychological science: social, personal, and cultural aspects. Taylor \& Francis, Hove, England, 1998, 51-71.

[11] Barber, L.K., and A.M. Santuzzi, "Please respond ASAP: Workplace telepressure and employee recovery.", Journal of Occupational Health Psychology 20(2), 2015, pp. 172-189.

[12] Barley, S.R., D.E. Meyerson, and S. Grodal, "E-mail as a Source and Symbol of Stress", Organization Science 22(4), 2011, pp. 887-906.

[13] Beaudry, and Pinsonneault, "Understanding User Responses to Information Technology: A Coping Model of User Adaptation”, MIS Quarterly 29(3), 2005, pp. 493-524. [14] Beaudry, and Pinsonneault, "The Other Side of Acceptance: Studying the Direct and Indirect Effects of Emotions on Information Technology Use", MIS Quarterly 34(4), 2010, pp. 689-710.

[15] Bichteler, J., "Human Aspects of High Tech in Special Libraries.", Special Libraries 77(3), 1986, pp. 121-28.

[16] Brod, C., "Managing technostress: optimizing the use of computer technology.", The Personnel journal 61(10), 1982, pp. 753-7.

[17] Brown, R., J. Duck, and N. Jimmieson, "E-mail in the workplace: The role of stress appraisals and normative response pressure in the relationship between e-mail stressors 
and employee strain.", International Journal of Stress Management 21(4), 2014, pp. 325-347.

[18] Chen, G., S.M. Gully, and D. Eden, "Validation of a New General Self-Efficacy Scale", Organizational Research Methods 4(1), 2001, pp. 62-83.

[19] Chen, S., M. Westman, and D. Eden, "Impact of enhanced resources on anticipatory stress and adjustment to new information technology: A field-experimental test of conservation of resources theory.", Journal of Occupational Health Psychology 14(3), 2009, pp. 219-230.

[20] Chin, W.W., and P.R. Newsted, "Structural equation modeling analysis with small samples using partial least squares", In Statistical Methods for Small Sample Research. Hoyle, Thousand Oaks, 1999, 307-342.

[21] Çoklar, A.N., and Y.L. Şahin, "Technostress levels of social network users based on ICTS in Turkey", European Journal of Social Sciences 23(2), 2011, pp. 171-182. [22] Costa Jr., P.T., and R.R. McCrae, "Personality: Another 'Hidden Factor' is Stress Research", Psychological Inquiry 1(1), 1990, pp. 22-24.

[23] Craig, A.R., J.A. Franklin, and G. Andrews, "A scale to measure locus of control of behaviour.", The British journal of medical psychology 57 ( Pt 2), 1984, pp. 173-80.

[24] D'Arcy, J., T. Herath, and M.K. Shoss, "Understanding Employee Responses to Stressful Information Security Requirements: A Coping Perspective", Journal of Management Information Systems 31(2), 2014, pp. 285-318. [25] Davis, F.D., "Perceived Usefulness, Perceived Ease of Use, and User Acceptance of Information Technology", MIS Quarterly 13(3), 1989, pp. 319-339.

[26] Day, A., S. Paquet, N. Scott, and L. Hambley, "Perceived information and communication technology (ICT) demands on employee outcomes: The moderating effect of organizational ICT support.”, Journal of Occupational Health Psychology 17(4), 2012, pp. 473-491. [27] Egan, O., "The concept of belief in cognitive theory", In L.P. Mos, ed., Annals of theoretical psychology. Springer publishing company, Boston, MA, USA, 1986.

[28] Fischer, T., and R. Riedl, "Technostress Research: A Nurturing Ground for Measurement Pluralism?", Communications of the Association for Information Systems 40(1), 2017, pp. 375-401.

[29] Fishbein, M., and I. Ajzen, Belief, Attitude, Intention and Behavior: An Introduction to Theory and Research, Addison-Wesley Pub. Co, Reading, MA, 1975.

[30] Folkman, S., R.S. Lazarus, C. Dunkel-Schetter, A. DeLongis, and R.J. Gruen, "Dynamics of a stressful encounter: Cognitive appraisal, coping, and encounter outcomes.", Journal of Personality and Social Psychology 50(5), 1986, pp. 992-1003.

[31] Fornell, C., and D.F. Larcker, "Evaluating Structural Equation Models with Unobservable Variables and Measurement Error", Journal of Marketing Research 18(1), 1981, pp. 39-50.

[32] Fuglseth, A.M., and Ø. Sørebø, "The effects of technostress within the context of employee use of ICT", Computers in Human Behavior 40, 2014, pp. 161-170. [33] Galluch, P., V. Grover, and J. Thatcher, "Interrupting the Workplace: Examining Stressors in an Information Technology Context", Journal of the Association for Information Systems 16(1), 2015, pp. 1-47.
[34] Hair, J.F., G.T.M. Hult, C.M. Ringle, and M. Sarstedt, $A$ Primer on Partial Least Squares Structural Equation Modeling, Sage, Thousand Oaks, 2017.

[35] Hassin, R.R., H. Aarts, B. Eitam, R. Custers, and T. Kleiman, "Non-conscious goal pursuit and the effortful control of behavior", In E. Morsella, J.A. Bargh and P.M. Gollwitzer, eds., Oxford handbook of human action. Oxford University Press, 2009, 549-566.

[36] Henseler, J., C.M. Ringle, and M. Sarstedt, "A new criterion for assessing discriminant validity in variance-based structural equation modeling", Journal of the Academy of Marketing Science 43(1), 2015, pp. 115-135.

[37] Hsiao, K.-L., "Compulsive mobile application usage and technostress: the role of personality traits", Online Information Review 41(2), 2017, pp. 272-295.

[38] Jagpal, H.S., "Multicollinearity in Structural Equation Models with Unobservable Variables", Journal of Marketing Research 19(4), 1982, pp. 431-439.

[39] Kock, N., and P. Hadaya, "Minimum sample size estimation in PLS-SEM: The inverse square root and gammaexponential methods", Information Systems Journal 28(1), 2018, pp. 227-261.

[40] Krishnan, S., "Personality and espoused cultural differences in technostress creators", Computers in Human Behavior 66, 2017, pp. 154-167.

[41] Krosnick, J.A., A.L. Betz, L.J. Jussim, and A.R. Lynn, "Subliminal conditioning of attitudes", Personality and Social Psychology Bulletin 18(2), 1992, pp. 152-162.

[42] Krosnick, J.A., and R.E. Petty, "Attitude strength: an overview", In J.A. Petty and J.A. Krosnick, eds., Attitude strength: antecendents and consequences. Erlbaum Associates, Mahwah, NJ, 1995, 1-24.

[43] Lazarus, R.S., Psychological stress and the coping process, McGraw-Hill, New York, NY, USA, 1966.

[44] Lazarus, R.S., "Theory-Based Stress Measurement", Psychological Inquiry 1(1), 1990, pp. 3-13.

[45] Lazarus, R.S., "Coping theory and research: past, present, and future.", Psychosomatic Medicine 55(3), 1993, pp. 234-247.

[46] Lazarus, R.S., and S. Folkman, Stress, appraisal, and coping, Springer publishing company, New York, NY, USA, 1984.

[47] Lee, Y.-K., C.-T. Chang, Y. Lin, and Z.-H. Cheng, "The dark side of smartphone usage: Psychological traits, compulsive behavior and technostress", Computers in Human Behavior 31, 2014, pp. 373-383.

[48] Lefcourt, H.M., "Locus of Control", In Measures of Personality and Social Psychological Attitudes. Elsevier, 1991, 413-499.

[49] Lowry, P.B., J. Zhang, C. Wang, and M. Siponen, "Why Do Adults Engage in Cyberbullying on Social Media? An Integration of Online Disinhibition and Deindividuation Effects with the Social Structure and Social Learning Model", Information Systems Research 27(4), 2016, pp. 962986.

[50] Maddux, J.E., "Self-Efficacy: The Power of Believing You Can", In S.J. Lopez and C.R. Snyder, eds., The Oxford Handbook of Positive Psychology. Oxford University Press, 2009, 334-344.

[51] Maier, C., S. Laumer, C. Weinert, and T. Weitzel, "The effects of technostress and switching stress on discontinued 
use of social networking services: a study of Facebook use", Information Systems Journal 25(3), 2015, pp. 275-308. [52] McGrath, J.E., "Methodological problems in research on stress", In H.W. Krohne and L. Laux, eds., Achievement, Stress, and Anxiety. Hemisphere, Washington, DC, USA, 1982, 19-48.

[53] Ng, T.W.H., K.L. Sorensen, and L.T. Eby, "Locus of control at work: a meta-analysis", Journal of Organizational Behavior 27(8), 2006, pp. 1057-1087.

[54] Olson, M.A., and R.H. Fazio, "Implicit Attitude Formation Through Classical Conditioning", Psychological Science 12(5), 2001, pp. 413-417.

[55] Ortiz de Guinea, A., "A pragmatic multi-method investigation of discrepant technological events: Coping, attributions, and 'accidental' learning", Information \& Management 53(6), 2016, pp. 787-802.

[56] Ragu-Nathan, T.S., M. Tarafdar, B.S. Ragu-Nathan, and Q. Tu, "The Consequences of Technostress for End Users in Organizations: Conceptual Development and Empirical Validation", Information Systems Research 19(4), 2008, pp. 417-433.

[57] Riedl, R., H. Kindermann, A. Auinger, and A. Javor, "Technostress from a neurobiological perspective: System breakdown increases the stress hormone cortisol in computer users", Business and Information Systems Engineering 4, 2012, 61-69. http://www.

[58] Roldán, J.L., and M.J. Sánchez-Franco, "Variance-based structural equation modeling: Guidelines for using partial least squares in information systems research", In Research Methodologies, Innovations and Philosophies in Software Systems Engineering and Information Systems. IGI Global, 2012, 193-221.

[59] Rotter, J.B., "Generalized expectancies for internal versus external control of reinforcement.", Psychological Monographs: General and Applied 80(1), 1966, pp. 1-28. [60] Rydell, R.J., A.R. McConnell, D.M. Mackie, and L.M. Strain, "Of Two Minds", Psychological Science 17(11), 2006, pp. 954-958.

[61] Salanova, M., S. Llorens, and E. Cifre, "The dark side of technologies: Technostress among users of information and communication technologies", International Journal of Psychology 48(3), 2013, pp. 422-436.

[62] Salmerón Gómez, R., J. García Pérez, M.D.M. López Martín, and C.G. García, "Collinearity diagnostic applied in ridge estimation through the variance inflation factor", Journal of Applied Statistics 43(10), 2016, pp. 1831-1849. [63] Sheeran, P., P.M. Gollwitzer, and J.A. Bargh, "Nonconscious processes and health.", Health Psychology 32(5), 2013, pp. 460-473.

[64] Sherer, M., J.E. Maddux, B. Mercandante, S. PrenticeDunn, B. Jacobs, and R.W. Rogers, "The Self-Efficacy Scale: Construction and Validation", Psychological Reports 51(2), 1982, pp. 663-671.

[65] Soucek, R., and K. Moser, "Coping with information overload in email communication: Evaluation of a training intervention", Computers in Human Behavior 26(6), 2010, pp. 1458-1466.

[66] Sprigg, C.A., and P.R. Jackson, "Call centers as lean service environments: Job-related strain and the mediating role of work design.", Journal of Occupational Health
Psychology 11(2), 2006, pp. 197-212.

[67] Srivastava, S.C., S. Chandra, and A. Shirish, "Technostress creators and job outcomes: theorising the moderating influence of personality traits", Information Systems Journal 25(4), 2015, pp. 355-401.

[68] Stana, R., and H.W. Nicolajsen, "A Cautionary Tale: How Co-Constructed Work Obligations Lead to ICT-Related Technostress", Proceedings of the Annual Hawaii International Conference on System Sciences, IEEE Computer Society (2021), 6631-6640.

[69] Tams, S., K. Hill, A. Guinea, J. Thatcher, and V. Grover, "NeuroIS-Alternative or Complement to Existing Methods? Illustrating the Holistic Effects of Neuroscience and Self-Reported Data in the Context of Technostress Research", Journal of the Association for Information Systems 15(10), 2014, pp. 723-753.

[70] Tarafdar, M., C.L. Cooper, and J. Stich, "The technostress trifecta - techno eustress, techno distress and design: Theoretical directions and an agenda for research", Information Systems Journal 29(1), 2019, pp. 6-42.

[71] Tarafdar, M., E.B. Pullins, and T.S. Ragu-Nathan, "Technostress: negative effect on performance and possible mitigations", Information Systems Journal 25(2), 2015, pp. $103-132$.

[72] Tarafdar, M., Q. Tu, B.S. Ragu-Nathan, and T.S. RaguNathan, "The Impact of Technostress on Role Stress and Productivity", Journal of Management Information Systems 24(1), 2007, pp. 301-328.

[73] Tarafdar, M., Q. Tu, and T.S. Ragu-Nathan, "Impact of Technostress on End-User Satisfaction and Performance", Journal of Management Information Systems 27(3), 2010, pp. 303-334.

[74] Tu, Q., K. Wang, and Q. Shu, "Computer-related technostress in China", Communications of the ACM 48(4), 2005, pp. 77.

[75] Wang, L., and M. Lv, "Internal-External Locus of Control Scale", In Encyclopedia of Personality and Individual Differences. Springer International Publishing, Cham, 2017, 1-4.

[76] Wang, Q., N.A. Bowling, and K.J. Eschleman, "A metaanalytic examination of work and general locus of control.", Journal of Applied Psychology 95(4), 2010, pp. 761-768.

[77] Yu, T.-K., M.-L. Lin, and Y.-K. Liao, "Understanding factors influencing information communication technology adoption behavior: The moderators of information literacy and digital skills", Computers in Human Behavior 71, 2017, pp. 196-208.

[78] Zajonc, R.B., "Feeling and thinking: Preferences need no inferences.", American Psychologist 35(2), 1980, pp. 151175.

[79] Zhang, S., L. Zhao, Y. Lu, and J. Yang, "Do you get tired of socializing? An empirical explanation of discontinuous usage behaviour in social network services", Information \& Management 53(7), 2016, pp. 904-914.

[80] Zielonka, J.T., and F. Rothlauf, "Techno-Eustress: The Impact of Perceived Usefulness and Perceived Ease of Use on the Perception of Work-Related Stressors", Proceedings of the 54th Hawaii International Conference on System Sciences, Hawaii International Conference on System Sciences (2021). 